DOI: 10.12731/wsd-2018-4-258-272

УДК 616.89 (470.45)

\title{
ПРОБЛЕМА ТЕРРОРИЗМА И МЕДИЦИНСКАЯ ПОМОЩЬ ПОСТРАДАВШИМ (НАУЧНЫЙ ОБЗОР)
}

\author{
Дубинкин В.А., Халиман А.С.
}

Ежегодно увеличивается количество актов агрессии, приводящих к гибели людей и порождающих нестабильность в обществе. Согласно положению военной доктрины РФ, в мире ожидается увеличение частоты применения высокоточного оружия. Одновременно одной из основных внешних опасностей является быстрое распространение международного терроризма, из-за которого страдает в большей степени мирное население.

Цель настоящей работы - выявление современных тенденций явления терроризма и анализ работы модели бригадного оказания психолого-психиатрической помощи пострадавщим.

Результаты. В настоящей статье обоснована необходимость начала медицинской реабилитаџии пострадавших непосредственно на месте совершения теракта и доказана эффективность бригадной модели оказания психолого-психиатрической помощи. Раскрыты особенности диагностики острых стрессовых реакичий у пострадавших и свидетелей террористических актов, подчеркнута важность этих знаний для узкоспециализированных врачей.

Заключение. Результаты работы психолого-психиатрических бригад доказали эффективность модели бригадного оказания экстренной психологической помощи.

Ключевые слова: медичинская помощь; террористический акт; постттравматическое стрессовое расстройство; острые стрессовые реакции; психолого-психиатрическая помощьь.

\section{THE PROBLEM OF TERRORISM AND MEDICAL} ASSISTANCE IS POST-DATED (SCIENTIFIC REVIEW)

\author{
Dubinkin V.A., Khaliman A.S.
}

Every year, the number of acts of aggression increases, leading to the death of people and causing instability in society. According to the position of the 
military doctrine of the Russian Federation, the frequency of the use of precision weapons is expected to increase in the world. At the same time, one of the main external dangers is the rapid spread of international terrorism, because of which the civilian population is suffering to a greater extent.

The purpose of this work is to identify current trends in the phenomenon of terrorism and to analyze the work of the model of brigade psychosocial support for victims.

Results. This article substantiates the need to start medical rehabilitation of victims directly on the site of the terrorist act and the effectiveness of the brigade model of psycho-psychiatric care is proved. The features of the diagnosis of acute stress reactions among victims and witnesses of terrorist acts are revealed, and the importance of this knowledge for highly specialized doctors is emphasized.

The conclusion. The results of the work of psycho-psychiatric teams proved the effectiveness of the model of brigade rendering of emergency psychological help.

Keywords: medical aid; terrorist act; post-traumatic stress disorder; acute stress reactions; psycho-psychiatric help.

\section{Введение}

Исследования терроризма чрезвычайно актуальны, но, к сожалению, в отечественной психологии теоретических и практических разработок по этой проблеме сравнительно немного [1]. Террористический акт - действия, создающие опасность гибели людей и наступления иных тяжких последствий, совершаемые в целях дестабилизации деятельности органов власти. Терроризм во всех его формах и проявлениях и по своим масштабам и интенсивности, по своей бесчеловечности и жестокости превратился ныне в одну из самых острых и злободневных проблем глобальной значимости [3]. Одной из проблем на протяжении последних нескольких десятилетий стал терроризм, его беспрецедентный рост: увеличиваются масштабы террористической деятельности, число одиночных террористических актов, совершаемых террористами-смертниками, что находит свое отражение не только в росте числа терактов, но и в изменении самого характера террористической деятельности. Для устрашения населения террористы применяют новые, более совершенные методы [7].

Целью настоящей работы стало выявление современных тенденций явления терроризма и анализ методов медицинской помощи пострадавшим при терактах. 


\section{Современное состояние глобальной безопасности}

Геополитические интересы ведущих мировых держав и развивающихся государств с возрастающей частотой вступают в различные международные конфликты: Китай с Японией - за необитаемые острова Тихого океана; Япония, Китай, Южная Корея с КНДР за несанкционированное испытание Северной Кореей «компактного» ядерного потенциала; Иран с США - за развитие ядерной энергетики, военные интересы Киева в отношении непризнанных ДНР и ЛНР, а также не прекращающиеся военные столкновения между исламскими террористическими организациями, умеренной оппозицией и Сирийскими военными [2, 19, 24]. 27 января 2018 прогремел взрыв в дипломатическом квартале столицы Афганистана Вазир-Акбар-Хан, где расположены посольства зарубежных стран и правительственные здания. Многие здания были повреждены, в них выбило окна. По последним данным министерства здравоохранения страны, число погибших в результате взрыва в Кабуле возросло до 103 человек, еще 235 получили ранения. Ответственность за взрыв взяло радикальное движение «Талибан». Как сообщают СМИ, взрыв совершил террорист-смертник на заминированном автомобиле скорой помощи. Проблема, складывающаяся сегодня в сфере борьбы с терроризмом, приобретает международный и общенациональный характер. В ее решении должны быть задействованы не только отдельные специально создаваемые для этой цели антитеррористические центры или правоохранительные органы и спецслужбы, но и все государственные и общественные структуры $[6,9,27]$.

Сложность борьбы с терроризмом состоит еще и в том, что это не однородное явление. Эксперты-террологи выделяют около 200 видов современной террористической деятельности. Основными из них являются: политический терроризм, националистический терроризм, религиозный терроризм, криминальный терроризм $[17,35]$. Также выделяют государственный, этнический, экономико-криминальный, индивидуальный, революционный, экономический, уголовный, адресный, экотерроризм, биологический, международный, компьютерный виды терроризма $[16,18]$ В современном обществе самым молодым можно считать кибертерроризм (война в пространстве Интернета), но он скорее является средством достижения политических, идеологических, националистических, религиозных и криминальных целей, а также индивидуальный и патологический терроризм $[4,7]$.

Учеными различных отраслей гуманитарного знания посвящено множество научных исследований, в том числе и диссертационных работ по вопросам противодействия терроризму и террористической деятель- 
ности [16]. Зарубежными специалистами подготовлена и опубликована в начале текущего столетия специальная энциклопедия - энциклопедия терроризма $[3,15,34]$. Регулярно выходит в свет на английском языке международный журнал «Терроризм», в котором публикуются новейшие исследования в области политологии, криминологии, социологии и психологии терроризма $[19,33]$. В США и других зарубежных государствах, после крупных террористических актов, произошедших 11 сентября 2001 года в Нью-Йорке, стала активно формироваться криминология терроризма как самостоятельное научное направление $[2,31]$ и учебная дисциплина для учреждений высшего образования [4].

Как следует из приведенных выше сведений, проблема, складывающаяся сегодня в сфере борьбы с терроризмом, приобретает международный и общенациональный характер. В ее решении должны быть задействованы не только отдельные специально создаваемые для этой цели антитеррористические центры или правоохранительные органы и спецслужбы, но и все государственные и общественные структуры [9].

\section{Реали национальной безопасности в России}

В России за последнее десятилетие террористические акты стали не редким явлением, при этом постоянный рост угрозы террористических воздействий разного масштаба (преступление против личности, групповое убийство, массовая гибель граждан, диверсия по всей территории страны, крупномасштабная акция против мирового сообщества) происходит на фоне обострения политического, этнического и религиозного экстремизма, представляющих значительную опасность для жизненных интересов отдельной личности, общества и государства, политической, военной, экономической и экологической безопасности страны, ее конституционного строя, суверенитета и территориальной целостности $[10,29]$.

Террористический акт в Петербургском метрополитене - взрыв, произошедший 3 апреля 2017 года в 14:33 в Санкт-Петербурге на перегоне между станциями «Сенная площадь» и «Технологический институт». По версии Следственного комитета РФ, взрыв осуществил террорист-смертник Акбаржон Джалилов, гражданин России с 2011 года, узбек по национальности и уроженец Киргизии. В теракте пострадали 103 человека, 16 из них погибли (один из погибших - предполагаемый исполнитель теракта. На 4 апреля был госпитализирован 51 раненый.

В 2013 Волгограде в октябре и декабре произошло 3 теракта в крайне многолюдных местах: в троллейбусе, автобусе и железнодорожном вок- 
зале, где погибло 33 человека, 29 из которых погибли на месте, 80 пострадавших получили ранения различной степени тяжести, а 4 человека умерли в стационаре. В очаге поражения сотрудниками психолого-психиатрических бригад была оказана помощь 21 человеку: пострадавшим с ранениями легкой степени тяжести, работникам вокзала и очевидцам $[10,12,30]$.

\section{Современные методы оказания \\ медицинской помощи пострадавшим при терактах}

Вопросы оказания медицинской помощи пострадавшим при терактах являются междисциплинарной проблемой и объединяют область психологии, психиатрии, неотложной хирургии и терапии. Прежде всего это обусловлено сложностью происходящих в данной обстановке воздействий на пострадавших. При этом по месту оказания медицинской помощи общепринята трехэтапная система: непосредственно на месте; в стационаре; реабилитация $[10,32]$.

На первом этапе оказания медицинской помощи, как правило, выявляется у пострадавших, их родственников и свидетелей в $56 \%$ случаев явления острой стрессовой реакции. Чаще всего это проявлялось клинически как страх, истерическая реакция и плач, а также чувство подавленности, безнадежность, отчаяние, которые обострялись в опасности повторения теракта. Острая реакция на стресс - это расстройство, которое развивается в ответ на необычный физический или психический стресс на фоне психического здоровья и, как правило, стихает через несколько часов или дней $[8,14]$.

Обычно течение острой стрессовой реакции включает два периода [5]. На первом наблюдается растерянность с дезориентацией, сужением восприятия и снижением внимания. Затем развивается тревожное состояние, паника, нарастают проявления вегетативно-соматические симптомов и злобы, развиваются отчаяние или ступор. В большинстве случаев выраженность симптомов уменьшается через 24-48 часов после манифестации. После реакции может сохраняться частичная или полная амнезия $[10,13]$. Острое стрессовое расстройство часто сопровождается диссоциативными симптомами (ощущение отгороженности и потери связи с реальностью, бесчувствие, дереализация, деперсонализация и диссоциативная амнезия) [37]. Кроме того, наблюдаются повторяющиеся переживания травмирующих событий, избегание напоминаний о них и вегетативно-соматические проявления. Острое стрессовое расстройство является предшественником 
посттравматической стрессовой реакции, и если его длительность превышает 4 недели - ставится диагноз посттравматического стрессового расстройства [7].

Посттравматическое стрессовое расстройство - это затяжная реакция на стрессовое событие или ситуацию исключительно угрожающего или катастрофического характера. Типичными признаками являются эпизоды повторного переживания травмы в виде навязчивых воспоминаний, снов или кошмаров, возникающих на фоне хронического чувства «оцепенелости» и эмоциональной притупленности, отчуждения от других людей, отсутствия реакции на окружающее, ангедонии (снижения или утраты способности получать удовольствие) и уклонения от деятельности и ситуаций, напоминающих о травме. Изредка бывают острые вспышки страха, паники или агрессии, провоцируемые стимулами, вызывающими воспоминание о травме. Характерна повышенная вегетативная возбудимость с усилением реакции испуга и бессонницей. С вышеперечисленными симптомами и признаками обычно сочетаются тревога и депрессия, нередкой является суицидальная идеация, осложняющим фактором которой становится избыточное употребление алкоголя или наркотиков $[11,26]$.

Степень проявления стрессовых реакций зависит от индивидуальных свойств личности (ранимости и способности владеть собой). Отсюда вытекает сложность их диагностирования, особенно в условиях оказания экстренной помощи пострадавшим при терактах.

При анализе медицинской литературы установлено, что у всех пострадавших при терактах наблюдались общие симптомы острой стрессовой реакции $[4,8,12]$ :

- покраснение кожных покровов лица (у 30\% пострадавших);

- тахикардия (45\%);

- моторное напряжение мышечной мускулатуры (25\%).

Психологами во время работы с пострадавшими были зарегистрированы такие проявления острой стрессовой реакции как:

- опасения возможного повторения теракта (5\%);

- трудности в сосредоточении внимания и его сужение (25\%);

- отчаяние, безнадежность, потеря иллюзии Тейлора (утрата веры в то, что события в жизни поддаются контролю) (11\%);

- боязнь выходить на улицу и пользоваться общественным транспортом (15\%).

Таким образом, острая стрессовая реакция и посттравматическое стрессовое расстройство сопровождаются вегетативными проявлениями, 
затрагивающими все системы организма. Пусковым механизмом данного процесса является стресс. Часто врачи в стационарах при лечении таких больных основной упор делают на фармакологическую коррекцию вегетативной дисфункции. Но при прекращении медикаментозной терапии все психовегетативные симптомы возобновляются $[11,28]$.

Мы считает, что в первую очередь пострадавшим необходимо оказывать психотерапевтическую помощь, чтобы разрешить психологический конфликт, вызванный несоответствием сложившихся обстоятельств внешнего мира внутренним потребностям индивида. Общеизвестно, что у человека существует базовая потребность в безопасности и комфорте. Но условия внешнего мира не позволяют их удовлетворить, так как во время теракта заложник испытывает страх за свою жизнь и становится очевидцем гибели других людей. Все системы организма мобилизуются для борьбы с внешними агрессивными факторами. Когда реальная угроза исчезает, реактивность вегетативной системы остается на прежнем уровне, что в условиях мирного времени является патологией. Это обусловлено сильным раздражением центральной нервной системы и формированием доминанты (происходит зацикливание на стрессовом событии). Применение фармакологических препаратов у таких больных должно носить лишь вспомогательный характер. Основное лечебное мероприятие - психотерапия [36].

Существует три основные группы методов, с помощью которых можно оценить собственно психологическое состояние пострадавшего или свидетеля террористического акта:

- субъективно-оценочные методы (направленные на изучение осознаваемых компонентов психических состояний);

- объективные методы (психофизиологические методы и психологические проективные методики) - направленные на изучение неосознаваемых психических состояний;

- методы, направленные на изучение экспрессивного (поведенческого) компонента психических состояний $[8,10,11]$.

Все эти методы имеют свои особенности и недостатки. Но следует отметить, что именно психофизиологические методы и психологические проективные методики имеют большие преимущества перед остальными, так как их применение не провоцирует реакции защитного характера (как это делают субъективно-оценочные методы). Однако применение субъективно-оценочных методов дает возможность более качественно интерпретировать психическое состояние, проводить его дифференциальную 
диагностику. Ограниченность применения методов, оценивающих экспрессивный компонент, заключается в том, что часто отсутствует возможность обеспечить как прямое наблюдение за субъектом, так и наблюдение с использованием видеорегистрации поведения и мимики $[8,21]$.

Во время терактов в Волгограде 29-30 декабря психолого-психиатрическими бригадами использовался следующий алгоритм оказания помощи пострадавшим и их родственникам [30].

Первый этап включал в себя прибытие на место теракта специализированных бригад территориального центра медицины катастроф в составе врачей-психиатров, клинических психологов и медицинских сестер, оснащенных медицинскими укладками с психофармакологическими препаратами. Была произведена экстренная оценка ситуации на месте происшествия, установлено взаимодействие с психологической службой Главного управления МЧС России по Волгоградской области и отделением экстренной психологической помощи Волгоградского центра социальной помощи семье и детям «Семья». Были привлечены штатные психологи Минздрава и Минсоцзащиты Волгоградской области, открыта горячая линия телефона доверия МЧС России. Главной задачей было установление доверительного контакта с пострадавшими, их родственниками и родственниками погибших $[11,12]$.

На втором этапе помощь оказывалась в условиях стационара. Психологи осуществляли сопровождение родственников в отделения реанимации и при опознании тел погибших. Во время размещения пострадавших в стационаре применялась «дифференцированная госпитализация» [10, 25]. Прибывшие психологи Центра экстренной психологической помощи МЧС России и психологи Государственного научного центра социальной и судебной психиатрии им. В.П. Сербского провели повторный осмотр всех пострадавших. Было организовано круглосуточное дежурство врача-психотерапевта, работал круглосуточный телефон доверия - об этом была размещена информация в СМИ, а пострадавшие и их родственники получили специальные «памятки пережившему катастрофу» [11, 22].

Третий этап - оказание пролонгированной психофармакологической помощи пострадавшим, находящимся в стационаре, а также их родственникам. Работа психолого-психиатрических бригад территориального центра медицины катастроф, а затем и психологов отделения экстренной психологической помощи центра «Семья» заключалась в использовании индивидуальной и групповой терапии. В оказание помощи были включены следующие методики: 
- приемы активного слушания;

- психологическая поддержка;

- рациональна терапия;

- техника вентиляции эмоций;

- дыхательные техники [10, 20].

Затем была произведена оценка психологического состояния специалистов территориального центра медицины катастроф, участвовавших в ликвидации медико-санитарных последствиях теракта, с целью профилактики развития посттравматического стрессового расстройства.

В результате, квалифицированную помощь получили 253 человека:

- 74 чел. - пострадавшие, находившиеся на стационарном лечении;

- 101 чел. - родственники пострадавших;

- 46 чел. - родственники погибших;

- 32 чел. - очевидцы теракта [10].

Итак, медицинская реабилитация включает комплексное применение лечебных факторов [14, 22], особое значение приобретает создание преемственности методов восстановительного лечения [23], поэтому врачам, работающим с пострадавшими при терактах, следует помнить, что исключительно фармакологический подход к лечению последствий тяжелых душевных потрясений ведет к подавлению симптомов, но не избавляет от причины расстройства, которое переходит в хроническую форму и отрицательно влияет на качество жизни пострадавшего, приводя к нарушению его социальной адаптации. Развитие медицинской науки вывело оказание специализированной медицинской помощи на новый уровень, что диктует необходимость изменения требований к подготовке кадров [11]. В связи с этим, назрела необходимость при постдипломной подготовке слушателей предусмотреть лекции по психолого-психиатрическим расстройствам людей, ставших жертвами террористических актов, что способствует формированию у врачей необходимых компетенций, касающихся организации оказания помощи в зоне теракта, своевременной диагностике острых стрессовых реакций у пострадавших и их дальнейшей успешной реабилитации [4, 23].

\section{Заключение}

Проблема терроризма глобальна по своей сути, и нет ни одного государства в мире, которое может жить сегодня в полной уверенности в том, что это явление рано или поздно не коснется его граждан. Общество должно быть готово к тому, что борьба с терроризмом может при- 
обрести долговременный характер, а не сводиться лишь к проведению отдельных мероприятий. Приведенные в исследовании факты показали, что наиболее эффективным методом оказания медицинской помощи пострадавшим при теракте является интегральная модель межведомственного взаимодействия в виде работы психолого-психиатрической бригад территориального центра медицины катастроф при оказании экстренной психологической помощи.

\section{Список литературы}

1. Авдеев Ю.И. Основные тенденции современного терроризма // Современный терроризм: состояние и перспективы / Под ред. Е.И. Степанова. M., 2000. C. 157-175.

2. Агафонов А.Б. Современная государственная антитеррористическая деятельность США: (полит, аспекты, проблемы) : дис канд.политол. наук; Нижегор. гос. ун-т. Н. Новгород, 2000. 300 с.

3. Антонян Ю.М. Терроризм: криминологическое и уголовно-правовое исследование. М.: Щит, 1998. 306 с.

4. Баланчук В.Д. О необходимости повышения знаний студентов высших учебных заведения в вопросах оказания первой помощи и поведению в чрезвычайных ситуациях / В.Д. Баланчук, И.В. Пирумова, Е.А. Калиниченко и др. // Современная наука: актуальные проблемы и пути их решения. 2015. №9 (22). С. 55-57.

5. Беляев А.Ф. Здоровье моряков: проблемы и решения. М: Владивосток: Рус. остров, 2010. 312 с.

6. Блищенко В.И. Международно-правовые проблемы государственного терроризма: (на примере Чили): дис ... канд. юрид. наук: 12.00.10; Моск. гос. ин-т междунар. отношений МИД СССР. М., 1989.

7. Быховец Ю.В. Представления о террористическом акте и переживание террористической угрозы: Автореф. дис. ... канд. мед. наук. Москва, 2007. $3 \mathrm{c}$.

8. Вельтищев Д.Ю. Острые стрессовые расстройства: факторы прогноза и профилактики затяжного течения // Социальная и клиническая психиатрия. 2010; 10 (2): 48-51.

9. Дикаев С.У. Уголовная ответственность за терроризм: учеб. пособие; Уфим. юрид. ин-т МВД Рос. Федерации. Уфа, 2000. 75 с.

10. Дубинкин В.А., Агошков А.И., Малинина Е.В. Медицинская помощь в чрезвычайных ситуациях. Учебное пособие. Владивосток: Изд-во ДВФУ, 2016. 132 c. 
11. Дубинкин В.А., Тушков А.А. Медицина катастроф в условиях мирного и военного времени: монография. Владивосток: Издательский дом Дальневост. федерал. ун-та, 2013. $136 \mathrm{c.}$

12. Захаров Д. Терроризм - необъявленная война против человечества // Новый Акрополь. Философия, психология, наука, искусство 2001. № 5 (24). С. 5 -9.

13. Иванова Г.Е. Медицинская реабилитация в России. Перспективы развития // Вестник восстановительной медицины, 2013, №5. С. 3-8.

14. Иванова Г.Е., Стаховская Л.В., Репьев А.П. Правовые основы оказания помощи по медицинской реабилитации // Вестник восстановительной медицины. 2014; 1: 2-5.

15. Кабанов П.А. Виктимология терроризма: вопросы формирования и развития // Виктимология. 2016. №4 (10). С. 12-22.

16. Кара-Мурза С. Тезисы о терроризме [Электронный ресурс]. Режим доступа: http:// www.nuweb.jinr.ru

17. Либиг М. Стратегический контекст современного иррегулярного ведения войн [Электронный ресурс]. Режим доступа: http://www.Df.ru/ metuniv. consor.LIEBIG/html. (Приложение к журналу «Россия - 2010», M).

18. Метелев С.Е. Современный терроризм и методы антитеррористической деятельности. М.: Омск, 2008. 332 с.

19. Мирский Г. Современный терроризм в контексте глобализации // Мировая экономика и междунар. отношения. 2002. № 3. С. 36-46.

20. Ольшанский Д.В. Психология терроризма. СПб.: Питер, 2002. 228 с.

21. Ослон А. 10 тезисов о Новой Эпохе // Америка: взгляд из России (до и после 11 сентября). М., 2001.

22. Петрищев В. Е. Российское законодательство: профилактика терроризма // Современный терроризм: состояние и перспективы / Под ред. Е. И. Степанова. М., 2000. С. 200-216.

23. Пирогова И.А. Организация и проведение внутривузовского конкурса по оказанию первой помощи в условиях чрезвычайных ситуаций / И.А. Пирогова, А.В. Чукичев, Н.М. Шлепотина и др. // Вестник совета молодых учёных и специалистов Челябинской области. 2016. Т. 1. №2 (13). С. 15-20.

24. Преснякова Л. Теракты в США: что потом? // Америка: взгляд из России (до и после 11 сентября). М., 2001.

25. Резина Л.А. Первая медицинская помощь в условиях чрезвычайных ситуаций // Вестник СМУС. 2016. №3 (14). С. 45-49.

26. С чего начинается ваххабизм? [Электронный pecypc]. http://www.islam.ru.

27. Степанов Е.И. Введение: Терроризм как предмет конфликтологической экспертизы // Современный терроризм: состояние и перспективы / Под ред. Е. И. Степанова. М., 2000. С. 5-8. 
28. Терроризм: психологические и политические аспекты / Р. Лукабо, Х.Э. Фукуа, Д.П. Кенджеми, К. Ковальски [Электронный ресурс]. Режим доступа: http://www.agentura.ru.

29. Указ Президента РФ от 5 февраля 2010 года № 146 «О Военной доктрине Российской Федерации».

30. Шкарин В.В., Ярмолич В.А., Рогаевский А.А., Баканов С.М. Особенности организации и оказания медицинской помощи пострадавшим при террористических актах в Волгограде // Медицина катастроф. 2014; 3: 19-22.

31. American Psychiatric Association. Diagnostic and statistical manual of mental disorders: 4th ed. Washington (DC): American Psychiatric Association; 1994.

32. Gary LaFree, Joshua D. Freilich. The Handbook of the Criminology of Terrorism. Wiley-Blackwell, 2016. $632 \mathrm{p}$.

33. Kaplan J. History and Terrorism // The Journal of American History. 2011. June, pp. 101-107.

34. Kushner, Harvey W. Encyclopedia of Terrorism. Thousand Oaks, CA: Sage Publications, 2003. $538 \mathrm{p}$.

35. Rapoport D.C. Before the Bombs There Were the Mobs: American Experiences with Terror // Terrorism and Political Violence. №20. (April 2008), pp. 167-194.

36. The ICD-10 classification of mental and behavioral disorders: diagnostic criteria for research (10th revision). World Health Organization. Geneva: 1992.

37. Vanderhoof D.J.W. The Criminology of Terrorism. Pembroke, 2001. Brooks, Graham The criminology of terrorism: closing the gap. BSc dissertation, University of Portsmouth, 2007.

\section{References}

1. Avdeev Yu.I. Sovremennyy terrorizm: sostoyanie i perspektivy [Modern terrorism: state and prospects] / Ed. E. I. Stepanov. M., 2000. S. 157-175.

2. Agafonov A.B. Sovremennaya gosudarstvennaya antiterroristicheskaya deyatel'nost'SShA: (polit, aspekty, problemy) [Modern state anti-terrorist activity of the USA: (polit, aspects, problems)]. N. Novgorod, 2000. 300 p.

3. Antonyan Yu.M. Terrorizm: kriminologicheskoe i ugolovno-pravovoe issledovanie [Terrorism: criminological and criminally-legal research]. M.: Shchit, 1998. $306 \mathrm{p}$.

4. Balanchuk V.D., Pirumova I.V., Kalinichenko E.A. et al. Sovremennaya nauka: aktual'nye problemy i puti ikh resheniya. 2015. №9 (22), pp. 55-57.

5. Belyaev A.F. Zdorov'e moryakov: problemy $i$ resheniya [Seafarers' health: problems and solutions]. M: Vladivostok: Rus. ostrov, 2010. $312 \mathrm{p}$. 
6. Blishchenko V.I. Mezhdunarodno-pravovye problemy gosudarstvennogo terrorizma: (na primere Chili) [International legal problems of state terrorism: (on the example of Chile)]. M., 1989.

7. Bykhovets Yu.V. Predstavleniya o terroristicheskom akte i perezhivanie terroristicheskoy ugrozy [Representations about a terrorist act and the experience of a terrorist threat]. Moskva, 2007. 3 p.

8. Vel'tishchev D.Yu. Sotsial'naya i klinicheskaya psikhiatriya. 2010; 10 (2): 48-51.

9. Dikaev S.U. Ugolovnaya otvetstvennost'za terrorizm [Criminal responsibility for terrorism]; Ufim. yurid. in-t MVD Ros. Federatsii. Ufa, 2000. 75 p.

10. Dubinkin V.A., Agoshkov A.I., Malinina E.V. Meditsinskaya pomoshch'v chrezvychaynykh situatsiyakh [Medical assistance in emergency situations]. Vladivostok: Izd-vo DVFU, 2016. 132 p.

11. Dubinkin V.A., Tushkov A.A. Meditsina katastrof v usloviyakh mirnogo i voennogo vremeni [Medicine of disasters in conditions of peaceful and war time]. Vladivostok: Izdatel'skiy dom Dal'nevost. federal. un-ta, 2013. $136 \mathrm{p}$.

12. Zakharov D. Novyy Akropol'. Filosofiya, psikhologiya, nauka, iskusstvo 2001. № 5 (24), pp. 5-9.

13. Ivanova G.E. Meditsinskaya reabilitatsiya $v$ Rossii. Perspektivy razvitiya // Vestnik vosstanovitel'noy meditsiny, 2013, №5. S. 3-8.

14. Ivanova G.E., Stakhovskaya L.V., Rep'ev A.P. Vestnik vosstanovitel'noy meditsiny. 2014; 1: 2-5.

15. Kabanov P.A. Viktimologiya. 2016. №4 (10), pp. 12-22.

16. Kara-Murza S. Tezisy o terrorizme [Theses on terrorism]. http:// www.nuweb.jinr.ru

17. Libig M. Strategicheskiy kontekst sovremennogo irregulyarnogo vedeniya voyn [Strategic context of modern irregular warfare]. http://www.Df.ru/ metuniv.consor.LIEBIG $/ \mathrm{html}$

18. Metelev S.E. Sovremennyy terrorizm i metody antiterroristicheskoy deyatel'nosti [Modern terrorism and methods of antiterrorist activity]. M.: Omsk, 2008. $332 \mathrm{p}$.

19. Mirskiy G. Mirovaya ekonomika i mezhdunar. otnosheniya. 2002. № 3, pp. 36-46.

20. Ol'shanskiy D.V. Psikhologiya terrorizma [Psychology of terrorism]. SPb.: Piter, 2002. $228 \mathrm{p}$.

21. Oslon A. Amerika: vzglyad iz Rossii (do i posle 11 sentyabrya) [America: a view from Russia (before and after September 11)]. M., 2001.

22. Petrishchev V.E. Sovremennyy terrorizm: sostoyanie i perspektivy [Modern terrorism: the state and prospects] / ed. E. I. Stepanov. M., 2000. S. 200-216.

23. Pirogova I.A., Chukichev A.V., Shlepotina N.M. et al. Vestnik soveta molodykh uchenykh i spetsialistov Chelyabinskoy oblasti. 2016. V. 1. №2 (13), pp. 15-20. 
24. Presnyakova L. Amerika : vzglyad iz Rossii (do i posle 11 sentyabrya) [America: a view from Russia (before and after September 11)]. M., 2001.

25. Rezina L.A. Vestnik SMUS. 2016. №3 (14), pp. 45-49.

26. S chego nachinaetsya vakhkhabizm? [What does Wahhabism begin with?]. http://www.islam.ru.

27. Stepanov E.I. Sovremennyy terrorizm: sostoyanie i perspektivy [Modern terrorism: state and prospects] / Ed. E. I. Stepanov. M., 2000, pp. 5-8.

28. Lukabo R., Fukua X.E., Kendzhemi D.P., Koval'ski K. Terrorizm: psikhologicheskie i politicheskie aspekty [Terrorism: psychological and political aspects]. http://www.agentura.ru.

29. Ukaz Prezidenta RF ot 5 fevralya 2010 goda № 146 «O Voennoy doktrine Rossiyskoy Federatsii» [Decree of the President of the Russian Federation of February 5, 2010 No. 146 "On the Military Doctrine of the Russian Federation"].

30. Shkarin V.V., Yarmolich V.A., Rogaevskiy A.A., Bakanov S.M. Meditsina katastrof. 2014; 3: 19-22.

31. American Psychiatric Association. Diagnostic and statistical manual of mental disorders: 4th ed. Washington (DC): American Psychiatric Association; 1994.

32. Gary LaFree, Joshua D. Freilich. The Handbook of the Criminology of Terrorism. Wiley-Blackwell, 2016. $632 \mathrm{p}$.

33. Kaplan J. History and Terrorism. The Journal of American History. 2011. June, pp. 101-107.

34. Kushner, Harvey W. Encyclopedia of Terrorism. Thousand Oaks, CA: Sage Publications, 2003. $538 \mathrm{p}$.

35. Rapoport D.C. Before the Bombs There Were the Mobs: American Experiences with Terror. Terrorism and Political Violence. №20. (April 2008), pp. 167-194.

36. The ICD-10 classification of mental and behavioral disorders: diagnostic criteria for research (10th revision). World Health Organization. Geneva: 1992.

37. Vanderhoof D.J.W. The Criminology of Terrorism. Pembroke, 2001. Brooks, Graham The criminology of terrorism: closing the gap. BSc dissertation, University of Portsmouth, 2007.

\section{ДАННЫЕ ОБ АВТОРАХ}

Дубинкин Владимир Александрович, д.м.н., профессор кафедры безопасности жизнедеятельности и медицины катастроф Федеральное государственное бюджетное образовательное учреждение выстего образования «Тихоокеанский государственный медицинский университет» Минздрава России просп. Острякова, 2, г. Владивосток, 690002, Российская Федераиия 500609@bk.ru 
Халиман Анна Сергеевна, студент последнего курса Лечебного факультета Федеральное государственное бюджетное образовательное учреждение высшего образования «Тихоокеанский государственный медииинский университет» Минздрава России

просп. Острякова, 2, г. Владивосток, 690002, Российская Федераиия anny_beauty.95@mail.ru

\section{DATA ABOUT THE AUTHORS}

Dubinkin Vladimir Alexandrovich, MD, Professor

Pacific State Medical University

2, Ostryakova ave., Vladivostok, Primorskiy Region, 690095, Russian Federation

500609@bk.ru

SPIN-code: 5912-7380

ORCID: 0000-0001-5242-5922

Scopus Author ID: 783297

Khaliman Anna Sergeevna, Student

Pacific State Medical University

2, Ostryakova ave., Vladivostok, Primorskiy Region, 690095, Russian Federation

anny_beauty.95@mail.ru

SPIN-code: 2816-9340

ORCID: 0000-0001-7025-0476 